\title{
Stressed-out, Self-isolated, and Hyper-connected: Teaching Today's Learners
}

\author{
Jeanette Landin \\ Landmark College
}

Today's learners bear a stress load of which their predecessors may never have dreamed. College students in the United States have financial and economic pressure. They have the perception that academic success is the only path to career success. Additionally, today's college students have become adults in an age where electronic connection is expected. An initial study found that college students reported academics as a significant pressure and that connecting face-to-face with and belonging to a group of peers is essential. Educators need to find a different way to teach today's learners that considers the students' academic success needs.

Keywords: Student Stress, Teaching, Electronics Use, Self-Isolation

\section{INTRODUCTION}

Consider this example of a typical American college student: He or she arrives at college with the ubiquitous earbuds and smartphone, memories of a discussion about college costs, and a previous attempt at college which may have been unsuccessful. Unfortunately, this example happens all too often across the United States, where a common perception is that academic success is a predictor of future affluence. The student will leave college, with or without an academic degree, loaded with a potentially lifelong burden of educational debt and unpredictable career prospects. The student hopes that maybe this college experience will be different. The student longs for old friends, but they are at other colleges trying to make their new friends.

Elsewhere on the campus, a professor puts the final touches on a syllabus that includes specific technology. The learning management system contains the semester's assignments and is ready. The professor eagerly awaits the first day of class to deliver the lessons that have historically been well received. The professor does not realize that the technology may prove to be another stressful burden that will end up overwhelming the student.

Both wish for the best, but that might not be the outcome. Teaching today's learners involves the recognition that they are under tremendous stress, self-isolated due to academic integrity demands, and continually connected. The technological tools purported to ensure success may not be as useful as promised, so educators must consider a more deliberate integration of tools to maximize their effectiveness. 


\section{SOURCES OF PRESSURE}

Today's college students are under similar pressures as their adult counterparts. They must deliver outstanding work, socialize appropriately, and manage their finances. In the United States, students claim that they experience anxiety more than two-thirds of the time they are in college (PR Newswire, 2018). However, students have not historically addressed the fear they face because they figure it is part of being in college. PR Newswire (2018) reported that 63 percent of students had not used the available resources at their college to address their anxiety. A 2012 study published by Ratanasiripong, Sverduk, Prince, and Hayashino pointed to the physiological and psychological effects of stress and pressure leading to decreased academic performance, medical problems, and suicide. Each source of tension leads to a sense of being overwhelmed when students are merely seeking the tools they need for their career.

\section{Pressure to Perform}

In the United States, achieving good grades in college is a high priority. Although the definition of what constitutes "good grades" differs among students, the cum laude designations and academic honor societies are highly prized and sought by students. Pisarik, Rowell, and Thompson (2017) noted that students associate course grades with career choice; therefore, the better the final score, the more opportunities that may become available, and the better chance to create a meaningful life. The student perceives that poor academic performance will limit career opportunities for worthwhile employment. In this author's experience, the pressure to perform has manifested in significant anxiety among students that leads to expressions of restlessness, fatigue, and irritability, symptoms associated with Generalized Anxiety Disorder (National Center for Biotechnology Information [NCBI], n.d.). It is essential to recognize this performance-related anxiety in the broader context of the other pressure college students experience.

\section{Social Pressure and Loneliness}

College students face a dichotomy: They are expected to participate in college-related social activities, ostensibly to form connections that may influence their career trajectory. Simultaneously, students much handle the academic demands of their coursework, much of which must be original, implying that they must work in some degree of solitude. Pittman and Richmond (2007) commented on the multifaceted transitions that students experience during college, such as living independently, developing satisfying social networks, but having to remain dependent to various extents on their family for emotional support. When these variables are combined, the reality of today's students emerges: Students in late adolescence or young adulthood who perceive pressure to make new friends but stay connected to their family, fund study partners but deliver undeniably original academic work, and often living in a unique situation (i.e., a dorm or an apartment) that has yet another set of social responsibilities. Over 60 percent of students have reported feeling lonely at college (PR Newswire, 2018) because of their social and other changes that they experience.

Another dimension to consider is the use of smartphones. Contemporary college students in the 18-24 range would not likely remember a time when smartphones did not exist. Although Lepp, Li, and Barkley (2016) found that the connectivity that smartphones offer has the potential to bring students together, the electronic connection is not a valid substitute for face-to-face human contact. The only senses involved in electronic communication are sight and sound, with the occasional touch when typing or otherwise holding the smartphone. In truth, no substitute for human contact truly exists. Because of the use of smartphones as a means of social connection, not to mention research, financial management, and the traditional telephone call, today's students have become habituated to superficial human contact, leading to the loneliness that so many students report - and that more do not. Moeller and Seehus (2019) noted that the reported rates and diagnoses of anxiety disorders and depression had risen significantly over the last five years preceding their publication. The question, What has changed to cause a rise in anxiety and depression among college students? It certainly is related to pressure or a perceived inability to meet 
expectations, either intrinsic or extrinsic. However, since the pressure to succeed in college has not significantly changed, then some other factor or factors must be driving this increase.

\section{Economic and Financial Pressure}

Another noted source of pressure on college students is monetary. The average annual cost to attend a public college or university in the United States was $\$ 13,544$ for the 2018-19 academic year (U.S Department of Education, 2019), and the average cost to attend a private, non-profit university, which is often more prestigious than public universities, was $\$ 48,510$ per year during the same period. Figure 1 contains a chart depicting the rise in college tuition costs between 2013 and 2019. An interesting note is a difference between public and private colleges, especially in light of the notion mentioned earlier of college degree attainment as a predictor of career success.

\section{FIGURE 1 \\ THE AVERAGE COST TO ATTEND COLLEGE IN THE UNITED STATES, 2013-2019, BY COLLEGE TYPE}

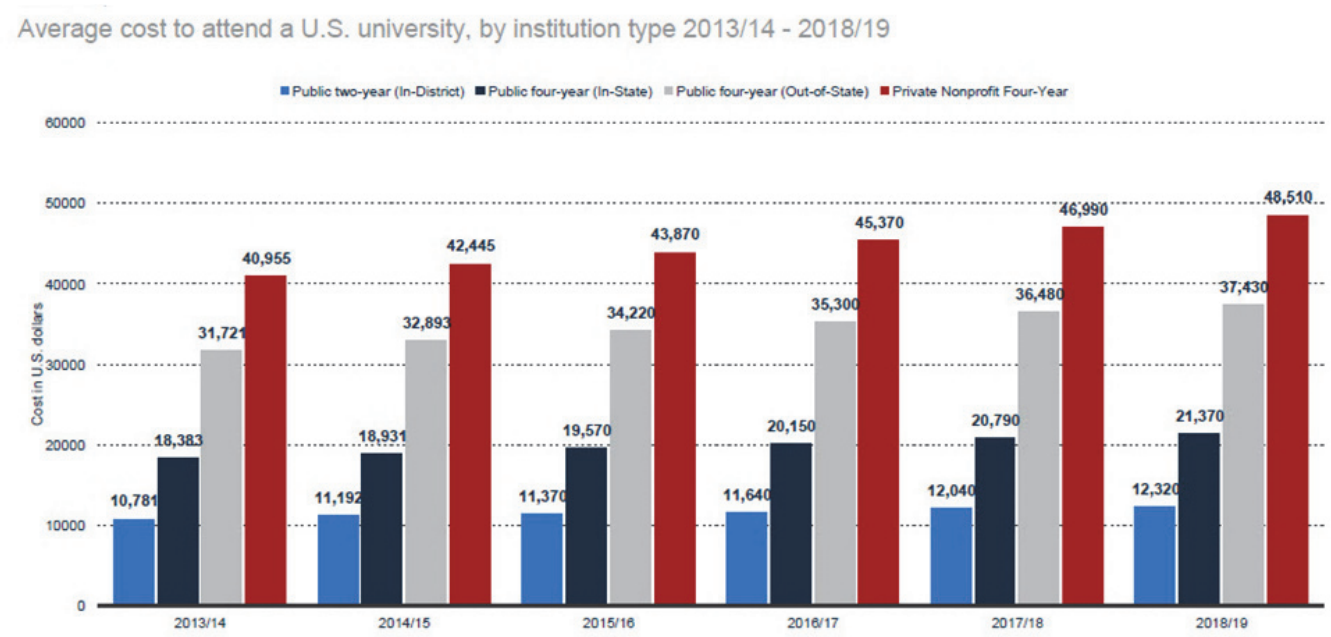

To obtain a baccalaureate degree in the United States is a substantial economic burden. According to the US Census Bureau (n.d.), the mean income for people varies according to their level of education and gender, although that is outside the scope of this study. Table 1 contains information about income levels associated with educational levels.

TABLE 1

CORRELATION OF EDUCATIONAL LEVEL AND INCOME RANGE IN THE UNITED STATES

\begin{tabular}{|c|c|c|c|c|}
\hline Educational Level & $\begin{array}{l}\text { Low } \\
\text { Income }\end{array}$ & Average & $\begin{array}{l}\text { High } \\
\text { Income }\end{array}$ & Average \\
\hline High School Diploma & $\$ 30,000$ & & $\$ 44,000$ & \\
\hline $\begin{array}{l}\text { Some college but no } \\
\text { degree }\end{array}$ & $\$ 30,000$ & & $\$ 47,000$ & \\
\hline Associate degree & $\$ 38,000$ & & $\$ 56,000$ & \\
\hline Baccalaureate degree & $\$ 53,000$ & & $\$ 81,000$ & \\
\hline
\end{tabular}

Considering the difference in earning power and the implied lifestyle, it leaves little room to wonder why young adults would want to pursue a baccalaureate degree in the United States. The problem many 
older adolescents and young adults face is obtaining the funds needed to achieve said Baccalaureate degree. If they are fortunate, their families can help pay for college. For those less fortunate, the alternative is to borrow the money, either from private lenders or the United States government. Figure 2 depicts the average amount of college debt for graduate and how it has risen from 2003-2017.

FIGURE 2

AVERAGE GRADUATE DEBT LEVELS, 2003 TO 2017

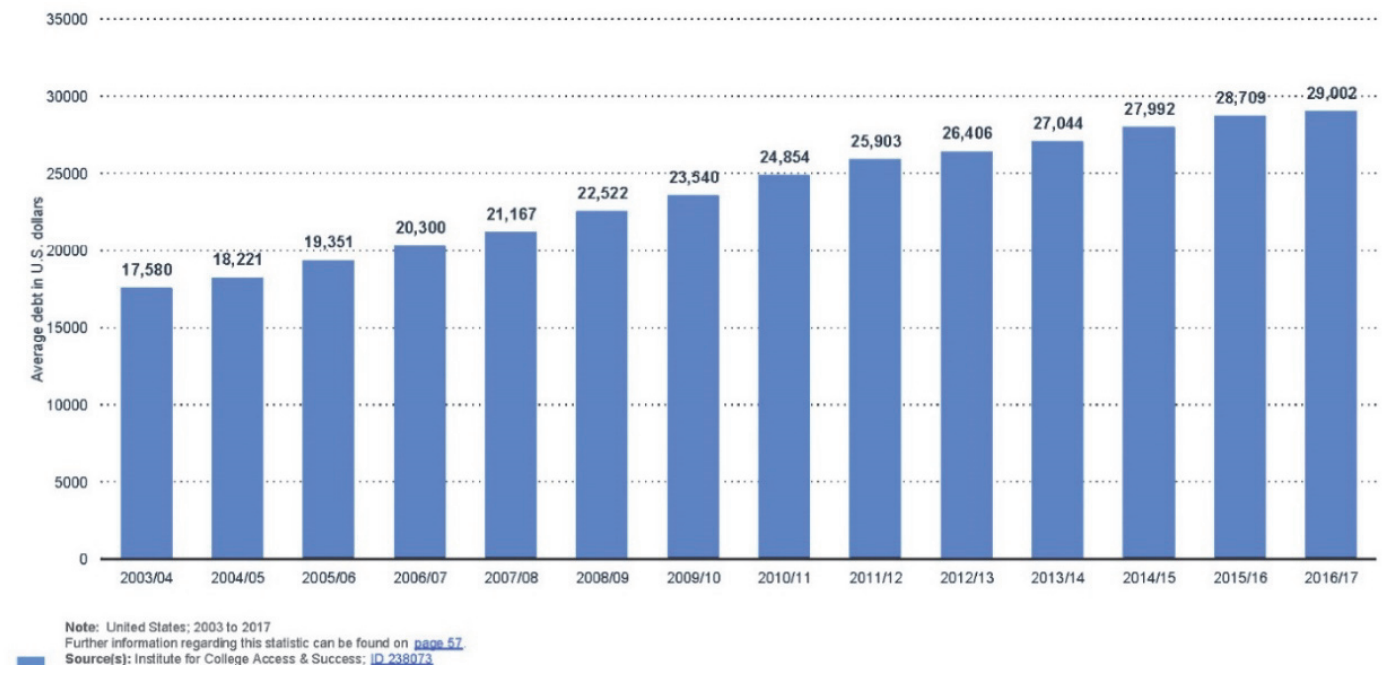

To summarize, students have a minimum of three pressures - to succeed, to connect, and to become economically secure - as part of their college journey, not to mention the achievement of the degree itself. College-aged students are developmentally transitioning from childhood to adulthood, and these additional pressures pile on like additional baggage of which the student may not have been previously aware. Another dimension exists, and that is the influence of the Internet and the constant connectedness that has become an inextricable part of students' lives. The paradox is that these devices present yet another challenge in their attainment of the education that is perceived to be the gateway to a successful future.

\section{THE INTERNET AND HYPER-CONNECTIVITY}

A mainstay of many older adolescents' and young adults' lives is the Internet and their connection to it. From this author's experience, it is rare to have a student who is not connected to the Internet, and usually through multiple devices. Their use of the internet is generally legitimate in that it helps them connect with friends, retrieve information, play games, and many other attractive, often necessary, activities. O'Donnell and Epstein (2019) wrote that today's students in the United States would almost prefer Internet connectivity than food because of the genuine need for friendships and connections as they transition to adulthood (Kim, Wang, \& Oh, 2016; Moeller \& Seehus, 2019). As college students, many courses require the use of Internet access for research, coursework completion, and occasionally course participation. Having taught and taken many Internet-based courses, this author understands the need for connectivity as part of successful degree completion. Add the pressure of successful completion of collegiate work to the social need for connection among older adolescents and young adults, and the immediate availability of both through the use of a smartphone or other internet-connected devices, and the result is hyper-connection to electronic media. 


\section{Interpersonal Communication and Loneliness}

The fact remains that students experience anxiety despite this continual electronic communication. Turkle (2017) wrote, "Technology is seductive when what it offers meets our human vulnerabilities" (p. 1). The chance to connect immediately via an electronic device such as a smartphone offers a quick way to avoid loneliness. Ironically, the very nature of that electronic communication is its ephemeral nature. These devices allow us to have conversations that seem face-to-face, but in truth, they are not. An electronic device, for all its utility and inherent usefulness, is genuinely a robot that is designed to make us happy. Quite literally, a person with a smartphone can find another person with whom to chat at any time of the day or night. Although the conversation may seem as sincere as an in-person interaction, the simple fact is that an electronic device will not and cannot replace actual human connection and that the only way to alleviate loneliness in any substantial way is through face-to-face interaction.

Furthermore, the use of smartphones in close relationships can become detrimental to users by reducing the mutuality and empathy that is present in face-to-face conversations (Chambliss et al., 2015). The feeling of connectedness via electronic device lasts hardly more prolonged than the connection itself, akin to eating sugar: The person feels satisfied for a short while but craves more sustenance shortly after that.

\section{The Use of Electronic Devices in the Classroom}

Another aspect of internet dependence is the way that the use of electronic media has affected course delivery and classroom practices. Today's students are "digital natives," meaning that technology has been a ubiquitous presence their entire lives and that they struggle to concentrate when they have no access to technology (Miller, 2014). Many studies have called this phenomenon Internet Addiction or IA, but it seems more like a natural resource such as electricity or running water that people in the United States take for granted as always being available. IA is a valid diagnosis in the DSM-V, but applying it broadly to an entire generation of people, such as the older adolescents or young adults, is unfair because the hallmarks of IA involve compulsive internet use (Poli, 2017). The Internet use for educational purposes does not meet the criteria for compulsive use or IA.

When appropriately used in education, Internet-based classroom and educational tools can promote engagement and enjoyment in the learning process. According to Doyle and Zakrajsek (2013), the more that learners connect new to previously known information, the better it sticks in the memory. However, as Carr (2011) pointed out, the use of the Internet for learning promotes a broad, yet shallow amount of understanding. The use of Google or other search engines to find information generally involves little long-term memory but increases the amount of cognitive load on short-term memory because of the need to remember multiple items such as links and items from various webpages. Carr (2011) noted that deep learning requires an anatomical change in the brain's structure over a long time, whereas short-term memory resides in synapses that do not last without reinforcement or connection. For example, many routines or mundane activities such as getting dressed or eating breakfast become unrememberable because the routine itself is embedded in long-term memory. While discovering new information (or conversing with friends) via the Internet promotes a jolt of endorphins that make the experience pleasurable, a lack of reinforcement of such knowledge fades because the event is often short-lived in nature. However, Cavanaugh (2016) suggested that embracing Internet activities because it engages students in pleasurable activity enlivens a classroom, which is exciting in itself. Based on the statistics presented in Figure 3, it appears that educators and students are as undecided as the research itself seems. 
FIGURE 3

ONLINE COURSE-RELATED ACTIVITIES REQUIRING A MOBILE DEVICE

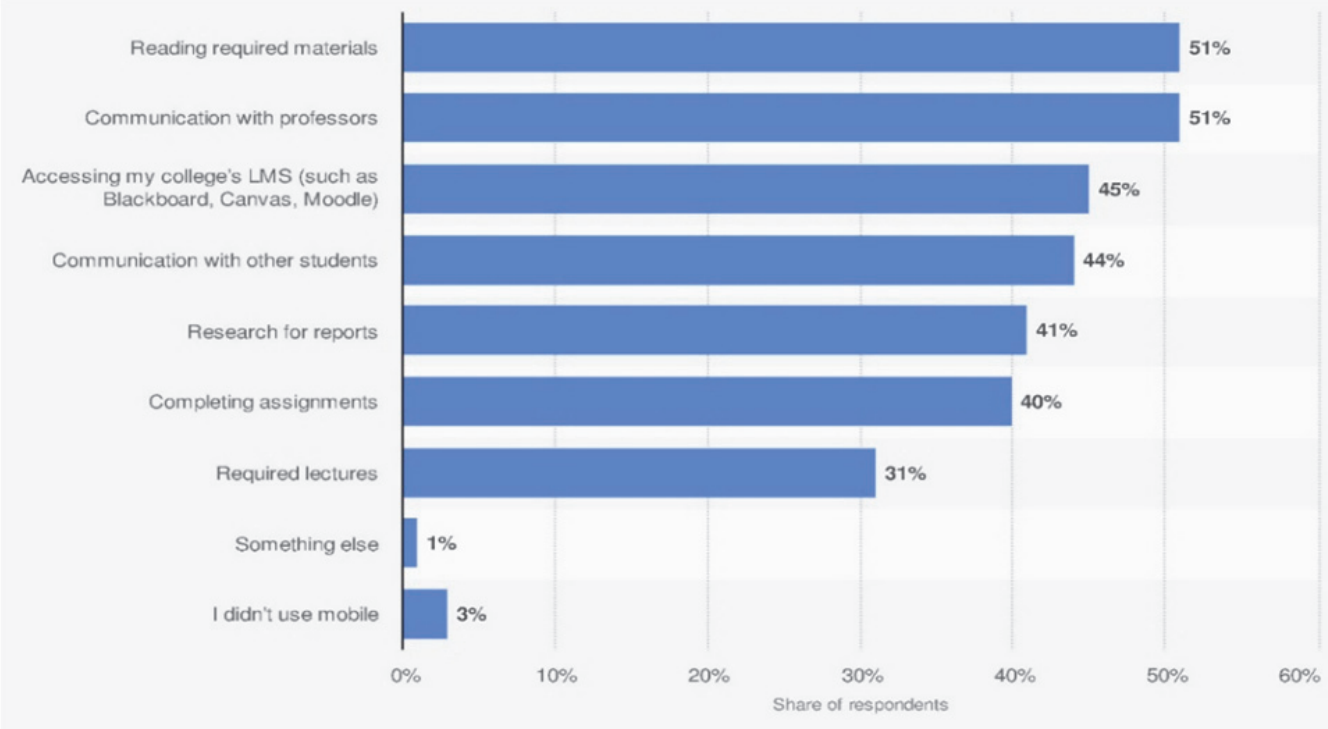

Remember that the information in Figure 3 only represents the respondents involved in the study and may not represent all college students. Figure 4 represents the students' view of the helpfulness of the use of technology as part of their class-related activities.

\section{FIGURE 4 \\ STUDENTS' VIEWS ON THE HELPFULNESS OF ONLINE STUDY TECHNOLOGIES}

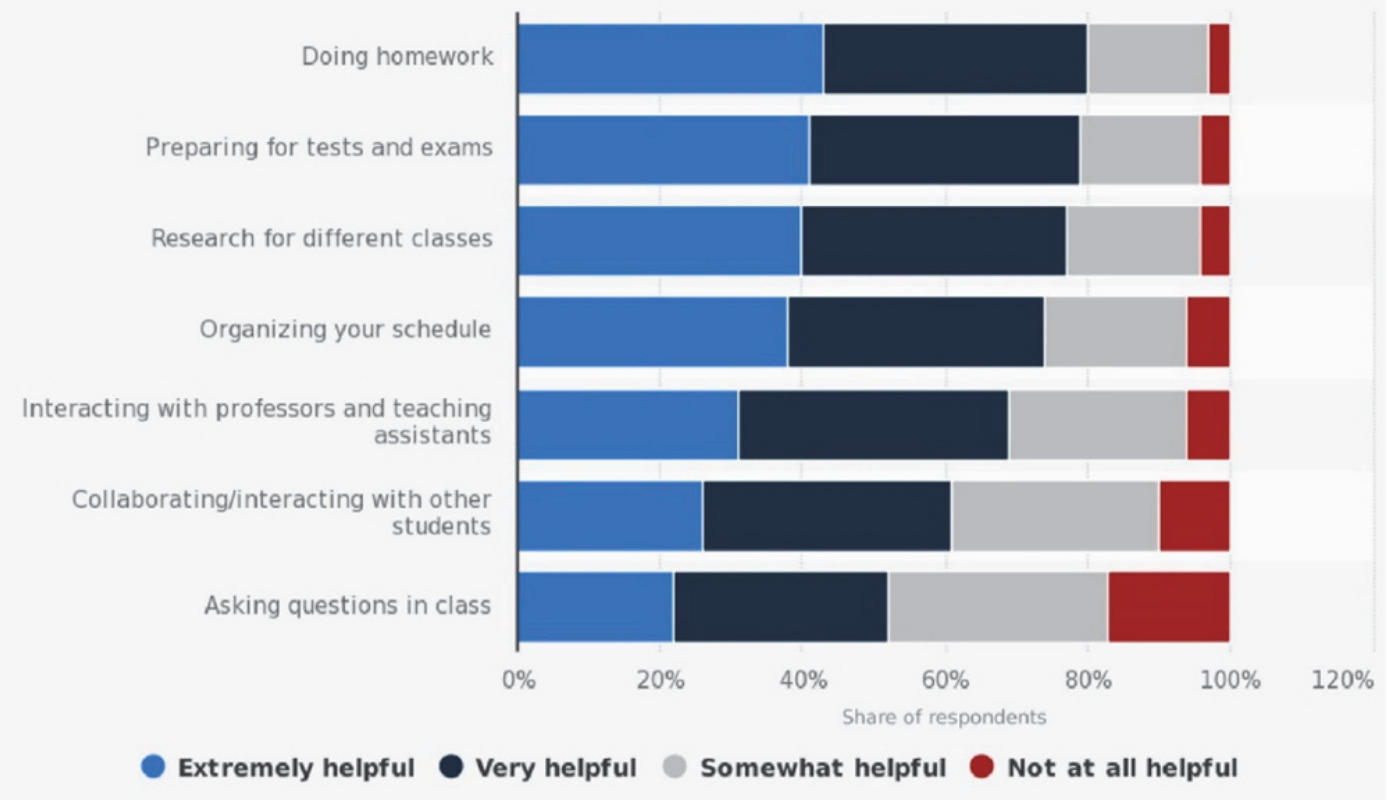

From the students' perspective, digital study tools were at least somewhat helpful most of the time. The disparity of educator and student perspectives highlights the differences in understanding of Internet use as a teaching tool. It also points to the fact that a significant percentage of college students use the 
Internet for schoolwork and other activities. The Observer (n.d.) found that 39 percent of adults aged 1829 in the United States use the Internet regularly. These statistics indicate that college-aged students on the Internet are profoundly connected to the Internet and rely on it for more than course work; they rely on it for communication with friends, accessing resources, and engaging in online gaming content (SuperData Research. (n.d.). To state that today's learners are hyper-connected to the Internet is a fact and that it affects teaching.

\section{THE NEED TO BELONG AND ITS EFFECT ON LEARNERS}

The need to belong, among older adolescents and young adults, transcends the need for many other more basic needs. This author remembers sleeping on friends' floors and remaining at gatherings until the wee hours of the morning to belong to a group of friends. According to O'Donnell and Epstein (2019), well over $90 \%$ of people in the United States between 18-29 years of age have and depend on a smartphone for connections with friends, school, and--quite literally--the world. Estimation of the actual time college students spend using their smartphones is nearly impossible, and the near-constant connection with the world, primarily through social media, self-reinforces the use.

\section{Hyper-connection}

The paradox lies in the use of smartphone technology, while connecting students in many ways, also create a sense of isolation (Lepp, Li, \& Barkley, 2016). A college-aged student needs to form peer relationships that complement parental bonds, and they can become overly dependent on technology to create these social relationships. However, the computer-mediated relationship lacks the face-to-face dimension that is inherent to interpersonal relationships. Vygotsky noted in the early $20^{\text {th }}$ century that interpersonal relationships require a context of symbols and culture (John-Steiner \& Mann, 1996). The smartphone, as an integral part of contemporary culture, inhibits the full cultural and social context of interactions by is electronic nature.

Furthermore, the use of social media, course platforms, and other computer-mediated forms of communication such as computer games and chats like Discord allow the user to have a level of anonymity that, for some, alleviates social anxiety. However, in a group setting such as a college classroom, when many students are online chatting, working on course work, or engaging in other activities, they are engaging in self-isolating practices. Young, Wang, and Oh (2016) noted that college students perceive that the use of smartphones as a way to facilitate social engagement. Conversely, Chambliss et al. (2015) commented that "constant connection to social media and text messaging can sometimes foster a disconnection with the real people sitting right in front of us" (p. 10), and force competition between human and virtual contact.

\section{The Effect on Learners}

College-aged learners must balance their time on social media with the other demands on their time. Rieth et al. (2003) commented that the structured use of electronics in the classroom is one way to work with technology instead of against it. That certainly is one approach, and at the time when of the article's publication, the contemporary Internet with the endless plethora of apps, games, and other utilities was still in its relative infancy. Marioara (2015) encouraged the deliberate integration of computer and Internet-based technologies to engages learners more fully. The trend, therefore, is toward embracing technology as a tool for educators and college students. Mendoza, Pody, Lee, Kim, and McDonough (2018) found that when students had the smartphone near them - in either the on or off position, in a backpack or bag - disrupted their learning and memory. However, asking the students not to bring the smartphone to class increased their anxiety and fear (Mendoza et al., 2018). Smartphones and classroom learning are complex topics because of how they both help and hinder students on many levels. 


\section{STUDENT STRESS AND BELONGING}

The convergence of student stress, smartphone use, the isolation involved in completing authentic academic work within the context of being hyperconnected and increasing student-reported anxiety piqued this author's interest because it seems like a nearly impossible situation to resolve. An initial survey-based study was conducted at a liberal arts college in the Northeastern United States in April and May 2019 to attempt a determination of a common theme or idea about how these items intersect. Upon IRB approval, the researcher contacted students at the college via email for their input about their questions. Participants had the option to quit the survey at any time. The researcher deliberately removed any specific identifying data from this initial study.

The school sampled had an enrollment of 340 students during the Spring 2019 semester, of which 98 $(N=98)$ completed the survey. The only demographics asked in this initial study were the student's age group and the number of semesters they had been in any college because those seemed to be the logical starting points for a study of this nature. Data were analyzed using IBM SPSS 26. Figure 5 contains a chart depicting the age group distribution.

FIGURE 5

DISTRIBUTION OF SURVEY RESPONDENTS BY AGE GROUP

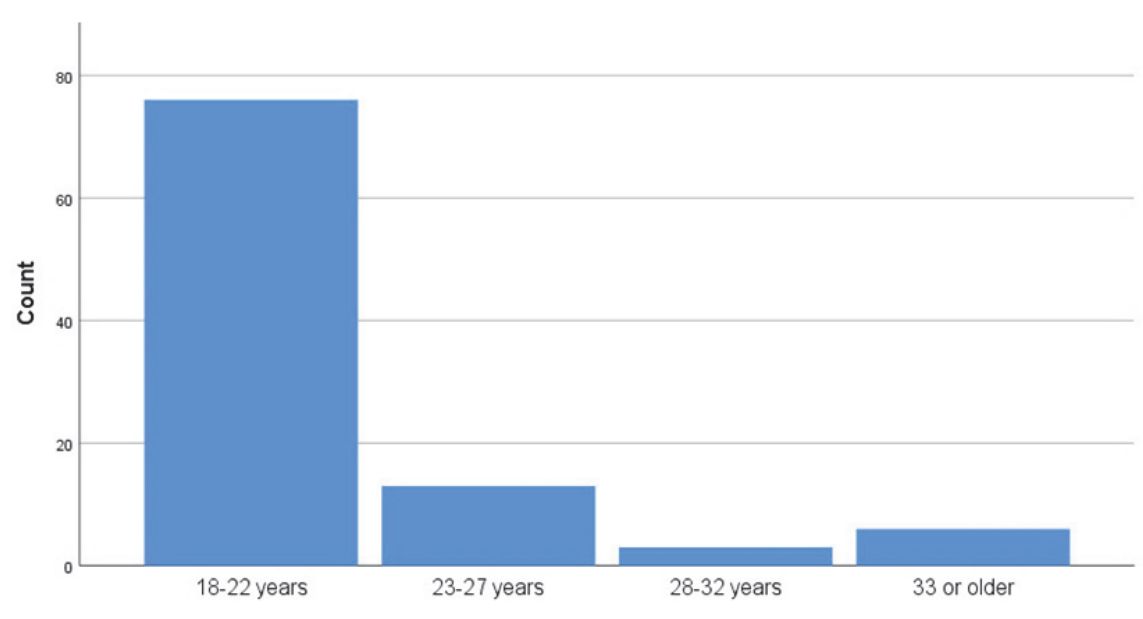

The number of semesters that the participants had spent in college was deemed an essential demographic question because of the economic effect of attending college. The graph depicting the distribution of the time the participants have spent in college is in Figure 6. 
FIGURE 6

DISTRIBUTION OF SURVEY RESPONDENTS BY TIME IN COLLEGE

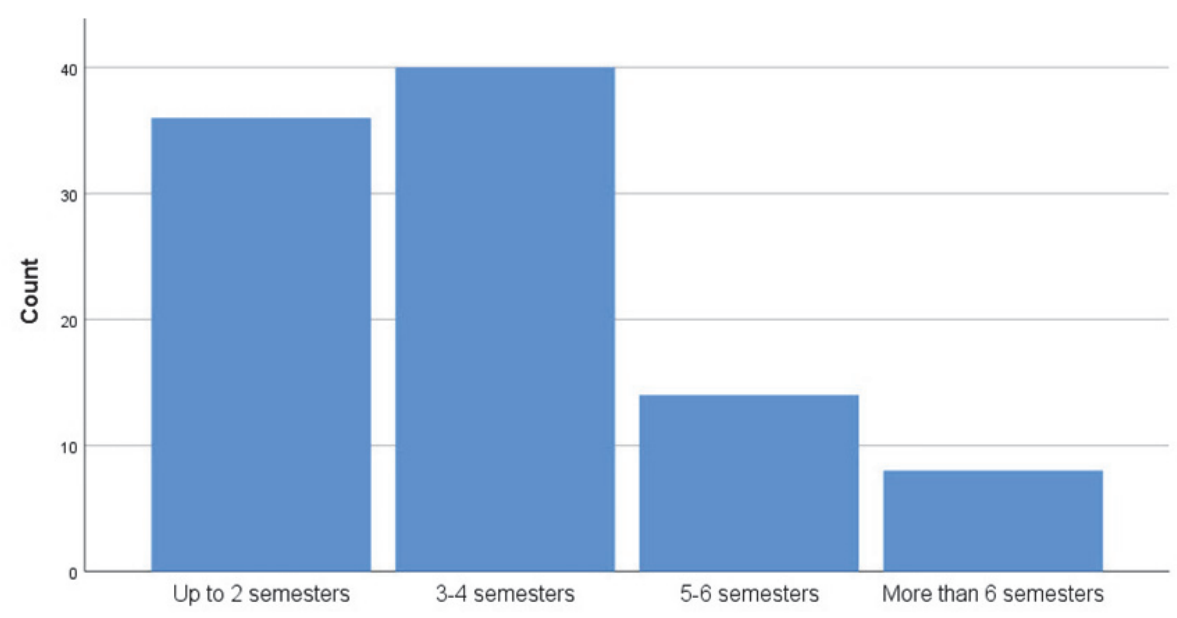

Based on the demographics alone, most respondents were between 18-22 years of age and had spent between 1-4 semesters in college. These results were impressive because of the aforementioned psychosocial development of people in this age bracket, which means that most respondents were of an age during which social relationships peak.

During this survey, participants answered the following questions:

1. How much time do you spend using online communication, gaming, or media such as YouTube?

2. How much time do you spend playing computer games on a daily basis?

3. How many friends do you regularly engage with on an in-person basis?

4. What methods of communication are you most comfortable using?

5. How much do you experience a sense of belonging at the College?

6. What do you perceive as the greatest cause of your stress?

The questions contained a four-point scale, with separate scales for each question, based on the attempt to identify the heart of the central problem of student anxiety. For the first question, the vast majority of participants reported spending 1-5 hours on social media such as Facebook, YouTube, gaming, or other internet-based social websites) daily, as shown in Figure 7. This amount is consistent with the amounts cited by Mendoza et al. (2018), so while it is a consideration in the hyper-connectedness of students, it was not a driver of the anxiety that pervades a single college. 


\section{FIGURE 7 \\ THE AMOUNT OF TIME REPORTED BY RESPONDENTS SPENT \\ DAILY ON SOCIAL MEDIA}

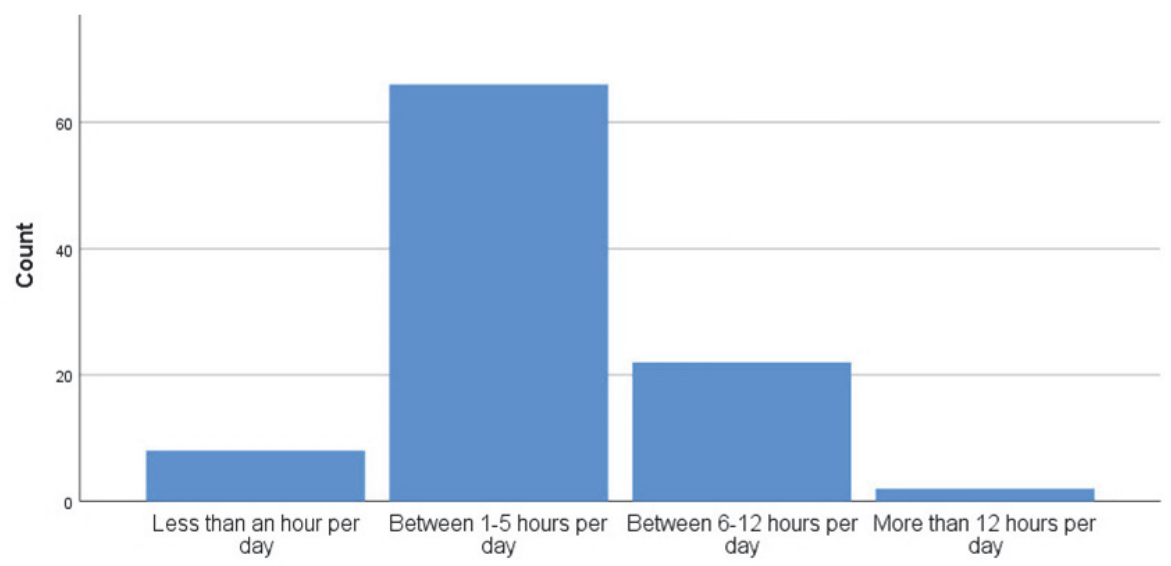

Of more importance than the simple distributions of demographics and time in social media were the correlations among specific questions. The most critical correlations involved the respondent's sense of belonging at the college. Correlations involving face-to-face (i.e., in-person, of FTF) friendships, age, stress, and time in college yielded the strongest Pearson correlations. Figure 8 contains the data about the correlation between FTF relationships and a sense of belonging at the college. The Pearson correlation, $r$, is .407 , demonstrating that the relationship between these two variables is not perfect but reasonably correlated.

FIGURE 8

\section{CORRELATION BETWEEN FTF RELATIONSHIPS AND A SENSE OF} BELONGING AT THE COLLEGE

\begin{tabular}{|c|c|c|}
\hline \multicolumn{3}{|l|}{ Correlations } \\
\hline & & How many friends do you have a personal, face-to-face relationship with on a regular basis? \\
\hline \multirow{3}{*}{$\begin{array}{l}\text { How many friends do you } \\
\text { have a personal, face-to- } \\
\text { face relationship with on } \\
\text { a regular basis? }\end{array}$} & Pearson Correlation & 1 \\
\hline & Sig. (2-tailed) & \\
\hline & $\mathrm{N}$ & 98 \\
\hline \multirow{3}{*}{$\begin{array}{l}\text { How much of a sense of } \\
\text { belonging do you feel at } \\
\text { the college? }\end{array}$} & Pearson Correlation & $.407^{\prime \prime}$ \\
\hline & Sig. (2-tailed) & .000 \\
\hline & $\mathrm{N}$ & 97 \\
\hline
\end{tabular}

The next correlation of interest involved the respondent's age and their sense of belonging. Figure 9 contains the data about the correlation, in which $r$ is -.225 , meaning that the older the student, the less they need to belong at the school. In terms of developmental psychology, this result makes sense because although the need to belong never indeed decreases, the way humans cope with negative emotions changes with age and the quality of relationships becomes more pressing than the quantity, and emotional goals become less of a priority (Charles \& Carstensen, 2014). 
FIGURE 9

CORRELATION BETWEEN A SENSE OF BELONGING AND AGE

\begin{tabular}{|c|c|c|}
\hline & & How much of a sense of belonging do you feel at the college? \\
\hline \multirow{3}{*}{$\begin{array}{l}\text { How much of a sense of } \\
\text { belonging do you feel at } \\
\text { the college? }\end{array}$} & Pearson Correlation & 1 \\
\hline & Sig. (2-tailed) & \\
\hline & $\mathrm{N}$ & 97 \\
\hline \multirow[t]{3}{*}{ What is your age group? } & Pearson Correlation & $-.225^{*}$ \\
\hline & Sig. (2-tailed) & .027 \\
\hline & $\mathrm{N}$ & 97 \\
\hline
\end{tabular}

Other correlations tested included time at the college vs. the need to belong, and the need for FTF relationships vs. time at the college yielded similar negative Pearson correlations, so it was determined that the number of friends and the quality of the relationships was the best clue in determining an answer to the questions of student stress, self-isolation, and pervasive electronic connections.

One of the other questions (number 6) involved the most significant stressor. Without question, academics were the greatest stressor, with over 60 percent of respondents identifying that choice. Curiously, fewer than 20 percent of respondents noted social issues as a source of stress, and a slightly larger percent reported "Other" issues as being stressful. Figure 10 contains a depiction of the distribution of stressors.

\section{FIGURE 10 \\ RESPONDENTS' IDENTIFICATION OF STRESSORS}

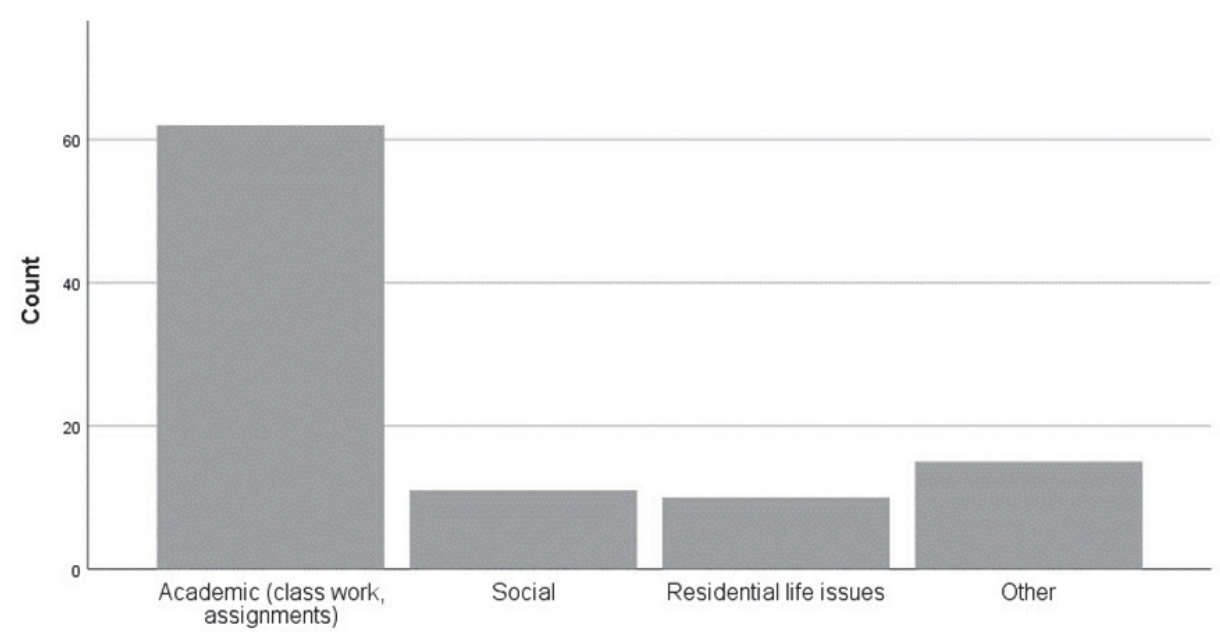

\section{DISCUSSION}

Based on the research and the study results, the following significant themes emerged:

1. Academic stress plays a significant role in students' lives.

2. Students strongly value FTF relationships.

3. Students, either by choice or coursework demands, spend significant time on electronic devices.

It was of interest that students also indicated "Other" as one of the stressors, more so than social reasons. Turkle (2017) commentary about the seductiveness of electronics and Mendoza, et al.'s (2018) notes about how electronics impede learning when turned on and in proximity to the student, combined with these other factors, lead to the idea that students are likely in physical proximity, but each on their 
own electronic devices and engaged in multiple simultaneous activities such as YouTube, Instagram, and coursework. In a sense, students are indeed together but immersed in their individual worlds.

\section{Limitations of the Study}

Study participants were limited to a single college in the Northeast United States, which led to small sample size. The small sample size limited the variety of responses, as did the quantitative nature of the questions. Students had four choices, and no two scales were alike, which limited the ability of the Likert scale to yield precise results. However, as an initial study to determine underlying causes and connections, a quantitative study was determined to be the optimal way to elicit answers respondents may not otherwise divulge.

Additionally, the quantitative nature of the study limited respondents' explanations of their responses. Especially in the case where students could select "other" as a cause of stress, that element is not measurable using quantitative methods. The small timeframe for the survey responses may have limited the number of respondents, and the fact that it was given toward the end of the Spring 2019 semester when workloads are typically the heaviest, may have affected the response to question number six. If the survey was given in the early part of the semester or at the beginning of the fall 2019 semester, the number of respondents experiencing social and residential life issues might receive more identification as a stressor.

\section{Biases}

This author will admit to a bias that students are stressed out and seem to always be online during class sessions. Granted, some students may use electronic devices for class notes and to search for facts during discussions, but may students use class time for Facebook, YouTube, online games, and other events. As a digital immigrant (i.e., someone born before the Internet, but a frequent and adept user nonetheless), this author has permitted and encouraged the use of computers and smartphones as a part of career preparation based on personal experience.

\section{CONCLUSIONS AND RECOMMENDATIONS FOR FUTURE RESEARCH}

College student stress, internet reliance, and loneliness is a problem, aggravated by the very technology that was designed to help them navigate and maximize their learning. As a result, educators may be exacerbating the problem and possibly hurting those who seek instruction by relying on technology as a teaching tool. Alleviating the problem is complex and may require paradigmatic shift in the way college educators teach. The answer to relieving stress, internet dependence, and loneliness the lies in more FTF contact between educators and learners and among learners themselves, but that answer leads to more questions and areas for future research.

Recommendations for future research include qualitative research into students' thinking about FTF interactions to understand more about how to integrate them more deliberately into coursework while maintaining academic integrity. Other studies might include quantitative research about precisely how much time college-aged students spend on different devices, what types of information they are accessing or transmitting, and how much of that time involves the simultaneous use of multiple devices (i.e., smartphone and computer) or multiple activities. Another avenue of interest would be to explore the interaction of neurodiversity with the themes of stress, self-isolation, and hyper-connectedness. Finally, qualitative research into the "other" stressors are that students identified would be worthwhile to determine what other demands students encounter. One thing is sure: Students in college are stressed-out, self-isolated, and hyper-connected, and the instructional use of technology may not be as beneficial as it seems. It is time that educators use technological tools more deliberately in constructed lessons that pull students together while using the available tools. Only then may professors leverage the power of the Internet and maintain the overall mental health of the learner. 


\section{REFERENCES}

Carr, N. (2017). What the Internet Is Doing to Our Brains: The Shallows. New York, NY: W. W. Norton. Cavanaugh, S. R. (2016). The Spark of Learning: Energizing the Classroom with the Science of Emotion. Morgantown, WV: West Virginia University Press.

Chambliss, C., Short, E., Hopkins-DeSantis, J., Putnam, H., Martin, B., Millington, M.,...Hartl, A. (2015). Young adults' experience of mobile device disruption of proximate relationships. International Journal of Virtual Worlds and Human Computer Interaction, 3, 10-17.

Charles, S., \& Carstensen, L. L. (2014). Social and emotional aging. Annual Review of Psychology, 61, 383-409.

Doyle, T., \& Zakrajsek, T. (2013). The New Science of Learning: How to Learn in Harmony with Your Brain. Sterling, VA: Stylus Publishing.

Institute for College Access \& Success. (n.d.). Average graduate debt levels in the United States from the academic year 2003/04 to 2016/17 (in U.S. dollars). In Statista - The Statistics Portal. Retrieved July 4, 2019, from https://libcat.landmark.edu:2224/statistics/238073/student-debt-in-the-us/.

John-Steiner, V., \& Mann, H. (1996). Social approaches to learning and development: A Vygotskian framework. Educational Psychologist, 31(3/4), 191-206.

Kim, Y., Wang, Y., \& Oh, J. (2016). Digital media use and social engagement: How social media and smartphone use influence social activities of college students. Cyberpsychology, Behavior, and Social Networking, 19(4), 264-270.

Learning House, \& AMR. (n.d.). For what online course-related activities do you use a mobile device? In Statista - The Statistics Portal. Retrieved July 4, 2019, from https://ibcat.landmark.edu:2224/statistics/944992/usa-mobile-device-usage-for-online-courserelated-activities/.

Lepp, A., Li, J., \& Barkley, J. E. (2016). College students' cell phone use and attachment to parents and peers. Computers in Human Behavior, 64, 401-408.

Marioara, L. (2015). The education change for in need student-centered learning. Procedia - Social and Behavioral Sciences, 191, 2342-2345.

McGraw-Hill. (n.d.). Views on the helpfulness of digital study technologies according to college students in the United States as of August 2016. In Statista - The Statistics Portal. Retrieved July 4, 2019, from https://libcat.landmark.edu:2224/statistics/662492/helpfulness-of-digital-studytechnologies-usa/.

Mendoza, J. S., Pody, B. C., Lee, S., Kim, M., \& McDonough, I. M. (2018). The effect of cellphones on attention and learning: The influences of time, distraction, and nomophobia. Computers in Human Behavior, 86, 52-60.

Miller, M. D. (2014). Minds Online: Teaching Effective with Technology. Cambridge, MA: Harvard University Press.

Moeller, R. W., \& Seehus, M. (2019). Loneliness as a mediator for college students' social skills and experiences of depression and anxiety. Journal of Adolescence, 73, 1-13.

National Center for Biotechnology Information [NCBI] (n.d.) DSM-IV to DSM-5 Generalized Anxiety Disorder Comparison. Retrieved from https://www.ncbi.nlm.nih.gov/books/NBK519704/table/ch3.t15/

O’Donnell, S., \& Epstein, L. H. (2019). Smartphones are more reinforcing than food for students. Addictive Behaviors, 90, 124-133.

Observer. (n.d.). Share of adults in the United States who are online almost constantly as of January 2018, by age group. In Statista - The Statistics Portal. Retrieved July 4, 2019, from https://libcat.landmark.edu:2224/statistics/497050/usa-adults-online-constantly-age/.

Pisarik, C.T., Rowell, P. C., \& Thompson, L. C. (2017). A phenomenological study of career anxiety among college students. The Career Development Quarterly, 65, 339-353.

Pittman, L. D., \& Richmond, A. (2007) Academic and psychological functioning in late adolescence: The importance of school belonging. The Journal of Experimental Education, 75(4), 270-290. 
Poli, R. (2017). Internet addiction update: diagnostic criteria, assessment and prevalence. Neuropsychiatry (London), 7(1), 04-08

PR Newswire (2018, September 28). High anxiety and stress for America's students from economic, political and social pressures, Chegg study shows. Santa Clara, CA: PR Newswire Association, LLC.

Ratanasiripong, P., Sverduk, K., Prince, J., \& Hayashino, D. (2012). Biofeedback and counseling for stress and anxiety among college students. Journal of College Student Development, 53(5), 742749 .

Rieth, H. J., et al. (2003). An analysis of the impact of anchored instruction on teaching and learning activities in two ninth-grade language arts classes. Remedial and Special Education, 24(3), 173184.

SuperData Research. (n.d.). Time spent watching gaming video content (GVC) in the United States in 2019, by age group. In Statista - The Statistics Portal. Retrieved July 4, 2019, from https://libcat.landmark.edu:2224/statistics/259586/time-teenagers-spent-per-video-gamingsession-in-the-us/.

Turkle, S. (2017). Alone Together. New York, NY: Basic Books.

US Census Bureau. (n.d.). Mean earnings in the United States in 2017, by highest educational degree earned and gender (in U.S. dollars). In Statista - The Statistics Portal. Retrieved July 4, 2019, from https://libcat.landmark.edu:2224/statistics/184248/mean-earnings-by-educationalattainment-and-gender/.

U.S. Department of Education (2019). The cost of college in the United States - Statistics \& Facts. Trends in College Pricing. Washington, D.C.: U.S. Department of Education. 